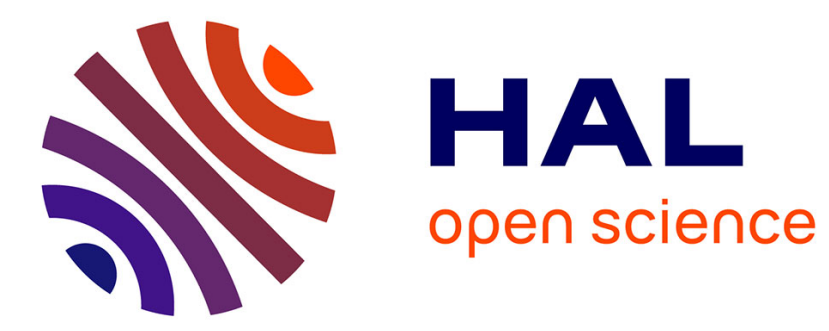

\title{
The Embodiment of Relationships of Adult Facebookers
}

\author{
Myrto Pirli, Sisse Finken, Christina Mörtberg
}

\section{To cite this version:}

Myrto Pirli, Sisse Finken, Christina Mörtberg. The Embodiment of Relationships of Adult Facebookers. 12th IFIP International Conference on Human Choice and Computers (HCC), Sep 2016, Salford, United Kingdom. pp.204-214, 10.1007/978-3-319-44805-3_17 . hal-01449461

\section{HAL Id: hal-01449461 \\ https://hal.inria.fr/hal-01449461}

Submitted on 30 Jan 2017

HAL is a multi-disciplinary open access archive for the deposit and dissemination of scientific research documents, whether they are published or not. The documents may come from teaching and research institutions in France or abroad, or from public or private research centers.
L'archive ouverte pluridisciplinaire HAL, est destinée au dépôt et à la diffusion de documents scientifiques de niveau recherche, publiés ou non, émanant des établissements d'enseignement et de recherche français ou étrangers, des laboratoires publics ou privés. 


\title{
The embodiment of relationships of adult Facebookers
}

\author{
Myrto Pirli $^{1}$, Sisse Finken ${ }^{2,3}$ and Christina Mörtberg ${ }^{3}$ \\ ${ }^{1}$ Computer Technology Institute and Press "Diophantus", Patras, Greece \\ myrtopirli@hotmail.com \\ ${ }^{2}$ IT University of Copenhagen, Copenhagen, Denmark \\ sisfeitu.dk \\ ${ }^{3}$ Department of Informatics, Linnæus University, Kalmar/Växjö, Sweden \\ \{sisse.finken, christina.mortberg\}@lnu.se
}

\begin{abstract}
In the last decade we have seen a rise of social media. Within this landscape of online services Facebook plays an immense role in facilitating and creating bonds between people. In this paper we enter a qualitative study conducted with a small group of adult Facebookers over 58. We do so in an effort to understand what kind of relationships one can have through this digital media. The theoretical lens used is Phenomenology, which we find fruitful for more carefully looking into relationships between humans and technology.
\end{abstract}

Keywords: Facebookers $\bullet$ older adults $\bullet$ embodiment

\section{Introduction}

In the last decade we have seen the rise of so-called social media, which are websites that allow members to connect to one another and share information about themselves, as well as photos and video [1]. The most popular of such sites can be argued to be Facebook where $67 \%$ of online adults are reported to be members in late 2012 [2]. In addition, Facebook reports that it has 1.55 billion monthly users as of 30th September 2015 [3]. Although people over 50 use social media less frequently than other demographics [1, 2] [4], their numbers are increasing fast. Madden [5] reports that the number of people over 50 who use social media doubled between 2009 and 2010.

Studying humans and their relation to technology is interesting in general, since, as Verbeek [6] says, we would not be the beings we are if we didn't use the technologies we use, with writing being a prime example. Here we draw on such comprehension and want to study more carefully the relation between humans and technology; i.e. the relation between a small group of users aged 58-73 (these people we refer to as Facebookers) and their varied engagements on Facebook. We do so with reference to this year's call for papers, which is concerned with technology and intimacy, and whether our relationship with technology is by choice or coercion. We address this call using phenomenology as the theoretical approach to study the embodiment of relationships of these Facebookers. 
In using relationship we equate it with intimacy. That is, according to Dictionary.com [7], intimacy is "a close, familiar, and usually affectionate or loving personal relationship with another person or group". Thus, when we look at this group of Facebookers and their online activities we are interested in the embodiment of such relationships. We draw on phenomenology, herein the postphenomenologist Don Ihde who coins embodiment as: "Embodiment is, in practice, the way in which we engage our environment or "world", and while we may not often explicitly attend to it, many of these actions incorporate the use of artifacts or technologies. [...] what I call embodiment relations, relations that incorporate material technologies or artifacts that we experience as taken into our very bodily experience." [8] (original emphasis). Thus, according to Ihde (also cited in [6] [9]), an "embodiment relationship" is one where we experience the world through an artifact, which is transparent to us and has become an extension of our body.

Whether a digital service like Facebook belongs to the category of "material technologies" we will leave out from the discussion here and rather focus our interest on understanding how, by using Facebook, our relationship with it can become an embodied relationship that leads to more intimate relationships between people. The reason we chose to study Facebookers over 58 is because this age group is less likely to use social media, even though they form a significant and growing proportion of Western population [10]. We therefore believe that it is interesting to study questions of technology and human relationships (intimacy) from the point of view of these people, who are often reluctant users.

The article has the following structure: First we briefly review related literature. We then describe the empirical setting and the methods used. This is followed by a description of the phenomenological concepts used. Next we meet eight Facebookers and enter an analysis about their varied engagements on Facebook. We then conclude the paper by advocating for analyzing varied engagements in an effort to learn about embodied relationships of adult Facebookers.

\section{$2 \quad$ Literature Review}

Different studies have been reported concerning Facebook and its usage. We begin this review with delineating studies concerned with social media and adults over 58, which are related to themes presented in this article. We then continue with studies about social media and types of relationships, social bonding, and intimacy.

Keeping in touch with friends and family was found to be a common motivation for using social media both by the general population [11] and by adults over 58 [5] [12]. It was also cited among the benefits of social media use [4, 5] [12, 13]. One of the barriers (for adults over 58) to joining and/or fully exploiting social media was found to be technical problems $[14,15]$, while some were hesitant to join because they viewed social media as cold and narcissistic and not fulfilling their idea of friendship [10] [14], and preferred face-to-face or email [14] [16].

Grieve et al. [17] found that social connectedness derived from Facebook is distinct but related to offline social connectedness; however, social disconnection can 
exist both in offline and online environments. Research shows that people tend to use social media more to keep in touch with people they already know offline, rather than meet new people $[18,19,20]$. In this, most add people they know offline [19]. There was an overlap between people's online and offline networks, but this was not perfect; some of their closest friends online were different from their closest friends offline [19]. In general, it seems that social network sites (SNS) play a supplemental role by providing another channel through which to maintain relationships [13] [21].

Using Facebook and MySpace as an extension of face-to-face interaction may strengthen existing relationships [4] [18] and broaden connections users would otherwise not have [18]. Gossip and small talk can serve as a form of social grooming for humans; SNSs can be used in that capacity [11]. According to Vitak, Ellison \& Steinfeld [21], Facebook use can have a positive effect not only on bridging social capital (weak ties), but also on bonding social capital (strong ties) when engaging in certain behaviors (commenting on a post rather than simply disclosing information). It can also be used, according to Ellison, Steinfeld \& Lampe [20], to solidify relationships that would otherwise be ephemeral, by converting latent ties into weak ties. Finally, Facebook may be useful for social bonding where face-to-face bonding is not possible, for example, in cases of people with high social anxiety [17], people who have difficulty forming both strong and weak ties [20], or when strong ties become geographically dispersed [20, 21].

Some people have expressed concerns about this new mediated life where face-toface communications tend to disappear or be replaced by mediated communications. This transformation has an impact on e.g. friendship, intimacy, and being in communities. Due to that, Deresiewicz (in [22]) argues, we have a sense of communities, rather than being in communities. In a similar way, Turkle $^{1}$ [22, p. 173, original italics] asks whether we, as a consequence of our use of social media services, have "moved from empathy to a sense of empathy? From friendship to a sense of friendship?". In line with this, we have previously mentioned a similar concern located in many adults over 58 [10] [14]. However, in Subrahmanyam et al.'s study [19], participants didn't think using SNSs affected their relationships. Vallor [23], examining what Aristotle named complete friendship of virtue, found that its four dimensions (reciprocity, empathy, self-knowledge and the shared life) are supported in some way by social media. Nevertheless, reflecting more deeply on the meaning of the shared life for Aristotle casts doubts about the capacity of online social media to support such friendships in the contemporary world, not only because of structural deficiencies of social media, but also of the modern world's values and priorities [23]. Van Manen [24] also states that although SNSs allow people to overcome physical distance and feel close while separated by time and space, such interaction does not necessarily result in more intimacy. He writes: "Digital intimacy may offer the sensibility of one-to-one closeness, but the one-to-one may be 'real' or illusory. [...] digital intimacy can be polygamous intimacy"2. On the other hand, Evans [25] comments that the idea of an imagined community is not new; during the Renaissance, a community of intellectuals was

1 [22] p. 173 (original emphasis)

2 [24] p. 6 
maintained via correspondence. He argues that "human experience has always been virtual to some extent" ${ }^{\prime 3}$, and states that for participants in virtual environments, the relationships are as authentic as those in the physical world.

\section{$3 \quad$ Methodology}

This article is based on material gathered during spring 2015 for the first author's phenomenological thesis work, whose purpose was to examine how and why adults in the age group 58-73 use Facebook, and what their experiences with Facebook are [26]. Eight people participated in the study, chosen from among the author's Facebook friends (see table 1$)^{4}$. The study was conducted using semi-structured interviews and observations of the participants' Facebook page and posts for a period of three weeks from 26/3/2015 to 16/4/2015.

Table 1. The participating Facebookers

\begin{tabular}{|c|c|c|c|c|c|c|}
\hline Name & Age & $\begin{array}{c}\text { Country of } \\
\text { origin }\end{array}$ & Work status & $\begin{array}{c}\text { Posting } \\
\text { frequency }\end{array}$ & $\begin{array}{c}\text { User } \\
\text { since }\end{array}$ & $\begin{array}{c}\text { Other } \\
\text { info }\end{array}$ \\
\hline Sophia & 58 & Greece & Retired & Low & 2010 & \\
\hline Jim & 59 & England & Retired & Medium & 2009 & \\
\hline Lotus & 60 & $\begin{array}{c}\text { England } \\
\text { (born in } \\
\text { Malaysia) }\end{array}$ & Retired & Medium & 2009 & $\begin{array}{c}\text { Married } \\
\text { to Jim }\end{array}$ \\
\hline Dimitris & 61 & Greece & Working & Low & Oct. 2014 & \\
\hline Joe & 62 & $\begin{array}{c}\text { Australia } \\
\text { (born in } \\
\text { England) }\end{array}$ & Working & Medium & 2012 & \\
\hline Sam & 65 & Australia & Retired & High & 2007 & \\
\hline Mary & 65 & USA & Working & Medium & 2012 & \\
\hline Tom & 73 & USA & Working & Medium & 2008 & $\begin{array}{c}\text { Married } \\
\text { to Mary }\end{array}$ \\
\hline
\end{tabular}

Here we meet all of these Facebookers; however, for the purpose of this article we have analysed the (interview) data anew from a perspective of embodiment and intimacy. Thus, in conjunction with writing this article, the participants were given a new consent form, which stated their agreement to using the data gathered in 2015 for scientific publication. When informed consent was originally obtained March 2015, they were also given a consent form along with a statement to post on their Facebook Timeline, which informed their friends about the study and provided contact information to the first author. The statement was posted in an effort to obtain consent of any

3 [25] p. 518

4 Names have been changed to protect privacy. 
friends who might interact with the participants on Facebook and therefore would be involved in the activities observed by the first author.

\section{Theory}

According to Schütz (in [27]), the contemporaneous lifeworld can be divided into two realms. The first is the realm of consociates, where people share a community of both time and space and their "worlds within reach" coincide (they meet "face-toface"). Through constant interaction in this realm people become intimate friends. The second realm is that of contemporaries, where people share neither a community of time nor of space. Their "worlds within reach" do not coincide and the only interaction they have is through a mediator, following prescribed rules. They are considered anonymous strangers [27].

Zhao [27, 28] suggests that with the advent of the Internet, we can gain mutual knowledge with strangers online, communicating in a "face-to-device" context. We can have people who share a community of time, but not a community of space, whose "worlds within reach" do not coincide but whose "worlds within mediated reach" do. These people he calls consociated contemporaries, who can also be characterized as intimate strangers or anonymous friends. The Internet can also be used to extend relationships in the consociates realm (friends and family) or the contemporaries realm (online business transactions).

Embodiment and disembodiment are also issues of phenomenology that are interesting to examine in relation to cyberspace. Ajana [29] contrasts Descartes belief in the supremacy of logical reason over illogical nature with Merleau-Ponty's belief in the body as the medium par excellence for being-in-the-world. Merleau-Ponty believed that it is through the body that we perceive and experience the world and that even in the case of transcendental disembodiment, the body is the point of departure, the point of return and the point of being. Therefore, Ajana [29] says, even in the virtuality of cyberspace, the construction of identity, subjectivity and self is based on bodily perceptions, resulting in a "pseudo-disembodiment". Rather than being free from bodily limitations, Ajana [29] notes how people carry their old baggage with them: women, for example, are still underrepresented and subject to harassment. Ajana [29] views cyberspace as "a symbiotic synthesis of technology and corporeal phenomena", likening virtual tools to a blind man's stick, which acts as an extension of his senses. He describes cyberspace as a case of being "embodied in one's disembodiment".

According to Dreyfus [30], the body's capacity to act is central to Merleau-Ponty's account of embodiment. Our embodied skills determine what actions we can take, and our relation to the world is transformed as we acquire new skills. Svanæs [31] adds to this that human interaction with digital technology is embodied. He refers to Heidegger, who said that for a skilled user, a tool is transparent in its use and "ready-tohand"; it is an extension of the user's body. This embodied interaction increases in relevance with the increase of proximity between the tool and the human body, where proximity means the tightness of coupling between the two. When a tool breaks 
down, this embodiedness also breaks and the tool ceases to be a tool and emerges as an object in the world.

\section{$5 \quad$ Facebookers and the Embodiment of Relationships}

\subsection{Becoming a Facebooker}

Joe, Sophia, and Sam joined Facebook in order to communicate and share things with other people. They share in common a positive experience using this online service.

Dimitris, on the other hand, had been more hesitant in joining; he had been receiving and ignoring friend invitations for years, before finally becoming convinced to join in order to be part of a group with his old school friends and cousins from his hometown. While before joining he had been terribly worried about privacy, he states that this has now radically changed. He repeatedly states how he really likes it, and how reading his friends' news in the group "makes [his] day".

Mary started using Facebook as part of her current job at a tour company, which does monthly tours and creates a Facebook page for each month's tour where people can post pictures and updates. Before working there she hadn't wanted to join Facebook because, as she says during an interview, it would take up too much of her time. Now she uses it not only as part of her job, but also to keep in touch with relatives and stay up-to-date with various clubs she and Tom belong to. Her view of Facebook is mainly positive; she says:

"I think it's wonderful, what [our boss] has done with Facebook in terms of RTours"

and

"It really is a wonderful mechanism to keep a big number of people informed about the schedules, the upcoming events, statuses and things like that"

(Interview with Mary, 23/3/2015, [Skype])

However, she does stress that one needs to be cautious while using it, referencing cyber-bullying and Facebook posts damaging people's hiring prospects. When asked what motivates her use of Facebook, she answers that it is both work and keeping in touch with people. In this way, we could say, Mary became a Facebooker because her job demanded it, but she now finds it useful in many other areas of her life; her intimacy with Facebook increased as she used it and, in this way, has become part of her embodiment of relationships.

Tom, on the other hand, joined much earlier, because he was curious and "it was the thing to do". However, he didn't like Facebook emotionally because he is a loner and it pushed him into contact with many people. This, combined with a fear of hacking and account misuse, led him to become disenchanted with Facebook. Now he keeps his accounts for work (he works at the same tour company as Mary), but his use consists mainly of monitoring through the email updates Facebook sends users. He only goes on Facebook occasionally, when something piques his interest or if Mary tells him about something interesting. So here we have an example of a "break down" (Heidegger in [31]) that decreases online relationship building and/or maintenance. 
Further, Tom expresses a preference for email, where he feels he can be more sure of his privacy and he can better control who sees what. So although he doesn't feel very intimate with Facebook, he feels more intimate with another, older technology (email).

Finally, Jim and Lotus joined and use Facebook, but they have certain reservations. Their main reason for joining was to be able to keep in touch with people while travelling, after they retired. In addition, Lotus wants to be able to keep in touch with their children. Jim says he really dislikes how Facebook uses people's data to make money and has considered quitting the platform because of this, but he continues to use it since it enables communication and because, compared to the 7 billion people on the planet, he isn't that important. Lotus feels the same way; she shares Jim's privacy concerns and has some negative perceptions about Facebook, but she finds the communication part nice. She says she wouldn't miss Facebook if she quit, but she would miss getting news about her friends.

Lotus, like Tom, expresses a preference for email, and also for using the telephone or meeting face-to-face. Interestingly, she says:

"[T]hey're just like the machines control your life, and I don't like that, I shouldn't like that. Old question of dialing up the telephone, talking to them..."

(Interview with Lotus, 21/3/2015, [Skype])

Within this analysis we can say that Lotus forgets that the telephone is also a technology, albeit one that has existed for longer and to which we are more used. As with Tom, we can see a pattern of feeling greater intimacy with older technologies, to the point of (in the case of the telephone) not really considering them machines at all. The longer a technology has been around, the more intimate people become with it and the more akin to it they feel. This follows along the lines of Lloyd [9], who states that there was a time when telephones were rare and the word "phony" was coined to describe the mistrust of a disembodied voice on the other side of the phone. Now phones are ubiquitous, and we accept disembodied thoughts as reality [9].

\subsection{Embodied Relationships and Intimacy on Facebook}

While all participants (with the exception of Tom) mention that communication is an important part of Facebook use for them, Joe and Dimitris stand out as examples where Facebook helps preserve and increase feelings of closeness with family and friends.

For Joe, who is originally from England, but has lived in Australia for the past 40 years, it is keeping in contact with family back in England and other parts of Australia that is main reason for joining in the first place. She describes how Facebook has enabled her to come in contact with nieces and nephews she has never met, as well as their children, and also re-establish contact with cousins she had met when she was much younger. She says:

"This morning I had a bit of a conversation with two of my nieces in Melbourne

[...] it's just a good way to start the day."

(Interview with Joe, 22/3/2015, [Skype]) 
Dimitris also describes how he communicates with old friends and relatives, people he had grown up with, and how, as soon as he joined Facebook, he found himself talking with people whom he hadn't talked with for a long time. He repeatedly says how it "makes [his] day", and how he, on occasion, has become emotionally moved at seeing old photos being shared. He tells that some of these friends got together offline and posted photos of this meeting in the group; this has inspired him to think about organizing his own offline meeting, for friends that are in the same city as he is, and posting about it in the group. So this can be seen as an example of Facebook strengthening offline bonds and potentially prompting offline meetings, a contradiction of concerns about online relationships leading to fewer offline meetings.

With regards to the types of relationships described by Schütz ${ }^{5}$ and Zhao $[27,28]$, examples of both the consociates and the consociated contemporaries can be seen among the participants. More specifically, all the participants except Tom mention using Facebook as an extension of the consociates relationship; to keep in touch with friends and family. There is also one example of consociated contemporaries relationships: Sam mentions that he also uses Facebook to meet new people who share common interests. Thus we see a confirmation of previous literature that Facebook is used mostly to maintain and strengthen offline relationships. However, there are some relationships that don't seem to fit either description. Joe, Lotus, and Sam all mention keeping in touch with people they met while travelling, while Tom and Mary use it to keep in touch with people that go on the tours they guide. Joe also came in contact, through Facebook, with family from England she has never met in person, or cousins she had met when she was much younger. These relationships cannot be described as consociates (intimate friends), but neither are they pure consociated contemporaries (intimate strangers or anonymous friends), because they know each other. We propose that this should be seen in one of two ways: either as an example of people who started a tentative consociates relationship when they met, which due to the short amount of time they spent together did not become a full consociates relationship, but which may become one as these people continue to interact and get to know each other through Facebook; or as a variation of the consociated contemporaries relationship, where people know each other slightly in real life and whom Facebook enables to become more intimate through their online interactions. Incidentally, these are also examples of Facebook helping transform latent, ephemeral ties into weak ties [20].

We see, thus, how Facebook affects intimacy for this group of Facebookers. That is, when they use it in order to extend consociates relationships, Facebook serves to maintain and increase an already established intimacy between them, their family and friends; when they use it to form consociated contemporaries relationships (or variations of this), Facebook helps transform lack of acquaintance (in the pure consociated contemporaries case) or mere acquaintance (in the modified case) into a greater degree of intimacy.

While Facebook lacks the physical cues of face-to-face communication, we believe it is very useful in cases where face-to-face is impossible, such as people sepa-

5 cited in [27] p. 93 
rated by great distance. Without Facebook, these people could not see or talk to each other regularly; Facebook enables them to talk, becoming an extension of people's corporeal ability to communicate, as Ajana [29] said. Joe comments that Facebook "seems to have made the world a smaller place", which shows how one's lifeworld can expand thanks to Facebook from the "world within reach" to the "world within mediated reach" $[27,28]$. These people can also "see" each other through posted photographs, or use Facebook's voice calls and video chat. In this study, Joe says that when she was on holiday, she posted photos regularly which enabled her children to share the experience with her, and Dimitris reports the posting of many photos, both past and present, in his Facebook group. Jim and Lotus also post family photos occasionally, and Sam posts photos of events he organizes. Thus technology helps these relationships become more embodied and more intimate.

In this way we can say, with reference to [6], that the artifact (here by example of an online service) and intimacy cannot be separated.

\section{Conclusion}

Verbeek [6] states that technology makes us who we are. Lloyd [9] adds that just like we have constructed the Internet, so has it constructed us.

In this article we have looked at different kinds of relationships, which a small group of adult Facebookers engage in using this online social service. We have shown how Facebook can be used to extend face-to-face ("consociates") relationships over long distance, facilitating them to become more intimate and embodied. It can also be used to increase intimacy between strangers ("consociated contemporaries") or between people who know each other very little in real life (what we term a variation of the "consociated contemporaries" relationship). Indeed, many of these relationships are intimately related to the online service forming an embodiment of relationships for the participating adult Facebookers..

\section{Acknowledgement}

Many thanks to the participants who made this study possible. Also, thanks a lot to the anonymous reviewers of $\mathrm{HCC} 12$.

\section{References}

1. Pfeil, U., Arjan, R., Zaphiris, P.: Age differences in online social networking - A study of user profiles and the social capital divide among teenagers and older users in MySpace. Computers in Human Behavior 25(3), 643-654 (2009)

2. Duggan, M., Brenner, J.: The demographics of social media users - 2012. Pew Research Center. http://www.pewinternet.org/files/oldmedia/Files/Reports/2013/PIP SocialMediaUsers.pdf (2013)

3. Facebook. Company Info. http://newsroom. fb.com/company-info/ (2015) 
4. Cornejo, R., Tentori, M., Favela, J.: Enriching in-person encounters through social media: A study on family connectedness for the elderly. International Journal of HumanComputer Studies 71(9), 889-899 (2013)

5. Madden, M.: Older adults and social media. Pew Research Center. http://www . pewinternet.org/ /media//Files/Reports/2010/Pew\%2 0Internet $\div 20-\% 2001$ der $\% 20$ Adults $\div 20$ and $\div 20$ Social $\div 20$ Media.pdf (2010)

6. Verbeek, P. P.: Cyborg intentionality: Rethinking the phenomenology of humantechnology relations. Phenomenology and the Cognitive Sciences 7(3), 387-395 (2008)

7. Dictionary.com, http://dictionary.reference.com/ (2016)

8. Ihde, D.: Postphenomenology and Technoscience: The Peking Univeristy Lectures. Suny Press, Albany (2009)

9. Lloyd, M. M.: There, yet not there: Human relationships with technology. Journal of Learning Design 3(2), 1-13 (2010)

10. Lehtinen, V., Näsänen, J., Sarvas, R.: A little silly and empty-headed: older adults' understandings of social networking sites. In: Blackwell, A. F. (ed.) Proceedings of the 23rd British HCI Group Annual Conference on People and Computers: Celebrating People and Technology. pp. 45-54. British Computer Society, Swinton (2009)

11. Wilson, R.E., Gosling, S.D., Graham, L.T.: A review of Facebook research in the social sciences. Perspectives on psychological science. 7(3) 203-220. (2012)

12. Harley, D., Fitzpatrick, G.: YouTube and intergenerational communication: the case of Geriatric1927. Universal Access in the Information Society. 8(1) 5-20 (2009)

13. Tsai, T. H., Chang, H. T., Wong, A. M. K., Wu, T. F.: Connecting communities: designing a social media platform for older adults living in a senior village. In: Stephanidis, C. (ed.) Universal Access in Human-Computer Interaction. Users Diversity. pp. 224-233. Springer, Berlin Heidelberg (2011)

14. Lüders, M., Brandtzæg, P. B.: 'My children tell me it's so simple': A mixed-methods approach to understand older non-users' perceptions of Social Networking Sites. New Media \& Society (online only) http://nms.sagepub.com/content/early/2014/10/09/146144481455 4064.full.pdf+html (2014)

15. Liu, C. J., Yang, S. C.: Using the Technology Acceptance Model to Examine Seniors' Attitudes toward Facebook. International Journal of Computer, Information, Systems and Control Engineering 8(6), 936-941 (2014)

16. Xie, B., Watkins, I., Golbeck, J., Huang, M.: Understanding and changing older adults' perceptions and learning of social media. Educational Gerontology 38(4), 282-296 (2012)

17. Grieve, R., Indian, M., Witteveen, K., Tolan, G. A., Marrington, J.: Face-to-face or Facebook: Can social connectedness be derived online? Computers in Human Behavior 29, 604-609 (2013)

18. Kujath, C. L.: Facebook and MySpace: Complement or substitute for face-to-face interaction?. Cyberpsychology, Behavior, and Social Networking 14(1-2), 75-78 (2011)

19. Subrahmanyam, K., Reich, S. M., Waechter, N., Espinoza, G.: Online and offline social networks: Use of social networking sites by emerging adults. Journal of Applied Developmental Psychology 29(6), 420-433 (2008)

20. Ellison, N. B., Steinfield, C., Lampe, C.: The benefits of Facebook "friends:" Social capital and college students' use of online social network sites. Journal of Computer-Mediated Communication 12(4), 1143-1168 (2007)

21. Vitak J., Ellison, N. B., Steinfield, C.: The ties that bond: Re-examining the relationship between Facebook use and bonding social capital. In: Sprague Jr, R. H. (ed.) Proceedings 
of the 44th Hawaii International Conference on System Sciences, pp. 1-10, CD-ROM. IEEE, Los Alamitos (2011)

22. Turkle, S.: Reclaiming conversation: the power of talk in a digital age. Penguin Press, New York (2015)

23. Vallor, S.: Flourishing on facebook: virtue friendship \& new social media. Ethics and Information technology 14(3), 185-199 (2012)

24. Van Manen, M.: The pedagogy of Momus technologies: Facebook, privacy, and online intimacy. Qualitative health research 10(1), 1-10 (2010)

25. Evans, S.: Virtual selves, real relationships: an exploration of the context and role for social interactions in the emergence of self in virtual environments. Integrative Psychological and Behavioral Science 46(4), 512-528 (2012)

26. Pirli, M.: Facebook use by the Less-frequently Using Demographic: A qualitative study. Master thesis, Dept. of Informatics, Linnaeus University, Sweden (2015)

27. Zhao, S.: Consociated contemporaries as an emergent realm of the lifeworld: extending Schütz's phenomenological analysis to cyberspace. Human Studies 27(1), 91-105 (2004)

28. Zhao, S.: Internet and the lifeworld: updating Schütz's theory of mutual knowledge. Information Technology \& People 20(2), 140-160 (2007)

29. Ajana, B.: Disembodiment and cyberspace: A phenomenological approach. Electronic Journal of Sociology 7, 1-10 (2005)

30. Dreyfus, H. L.: The Current Relevance of Merleau-Ponty's Phenomenology of Embodiment. In: Haber, H., Weiss, G. (eds) Perspectives on Embodiment. Routledge, New York and London (1996).

31. Svanæs, D.: Interaction design for and with the lived body: Some implications of merleauponty's phenomenology. ACM Transactions on Computer-Human Interaction (TOCHI) 20(1) (2013) 